\title{
Modeling pH Neutralization Process using Fuzzy Dynamic Neural units Approaches
}

\author{
Lyes Saad Saoud Fayçal Rahmoune Victor Tourtchine Kamel Baddari \\ Laboratory of Computer science, Modeling, Optimization and Electronic Systems (L.I.M.O.S.E), \\ Department of Physics, \\ Faculty of sciences, \\ University M'hamed Bougara of Boumerdes \\ Algeria
}

\begin{abstract}
In this paper, a new architecture combining dynamic neural units and fuzzy logic approaches is proposed for a complex chemical process modeling. Such processes need a particular care where the designer constructs the neural network, the fuzzy and the fuzzy neural network models which are very useful in black box modeling. The proposed architecture is specified to the $\mathrm{pH}$ chemical reactor due to its large existence in the real industrial life and it is a realistic dynamic nonlinear system to demonstrate the feasibility and the performance of the founding results using the fuzzy dynamic neural units. A comparison was made between four strategies, the fuzzy modeling, the recurrent neural networks, the dynamic recurrent neural networks and the fuzzy dynamic neural units.
\end{abstract}

\section{Keywords}

$\mathrm{pH}$ process; Dynamic neural units; Nonlinear system identification; Fuzzy modeling.

\section{INTRODUCTION}

The identification of system models is an important and integral part of control design methodology [1]. Several identification algorithms and approaches were proposed to overcome these problems. For example, in [2] the neural network proves to be an excellent mathematical tool for dealing with nonlinear problems. It can approximate any continuous nonlinear relation with arbitrary accuracy with a suitable architecture and weight parameters [3]. Fuzzy modeling is a useful technique for the description of nonlinear systems [4], in where nonlinear process behavior is approximated by multiple linear models with fuzzy transitions. It can be seen as logical models which use "if-then" rules to establish qualitative relationships among the variables in the model [5]. Combining the fuzzy logic and neural networks has been proposed in various works [6-12]. Integrate the fuzzy logic formalism with the learning ability of neural networks produce one promising approaches for modeling nonlinear systems [6].

Therefore, neural network and fuzzy neural network modelling should take into account the dynamics of processes. Two main methods exist to provide a static neural network with dynamic properties [3]: the insertion of an external memory to the network or the use of feedback or so-called Dynamic Neural Units (DNUs). The DNUs have been shown to possess good dynamic function approximation capabilities and have been applied successfully by [3, 13, 14 and 15] in identification of the nonlinear dynamic systems.

The $\mathrm{pH}$ process is widely used in various areas such as the neutralization of industrial waste water, the treatment of boiler feed water and cooling water in the cooling tower, and the maintenance of the desired $\mathrm{pH}$ level at various chemical reactions, coagulation and precipitation processes $[16,17]$. Its high nonlinearity and dynamic reaction give it the propriety to be a challenging problem for modeling. However and due to the importance of the $\mathrm{pH}$ chemical reactor in the industrial life, we can find several researchers in the literature considering the $\mathrm{pH}$ process not just as an example to prove the performance of their results in the modeling and in the control (e.g. [18-24]), but also they specified it by a special model such as Wiener model [2527].

In this paper, a new architecture combining the dynamic neural units and the fuzzy logic techniques to model the $\mathrm{pH}$ chemical reactor is proposed. The $\mathrm{pH}$ mathematical model contains two parts, the first one is dynamic which will be modeled using DNUs, and the second is static in which the fuzzy modeling approach is a good tool to represent it. This architecture groups the advantages of all the previous techniques and it takes into account the nonlinearity, the dynamics of the system and introduces the human thinking to produce a powerful model to the $\mathrm{pH}$ process.

After a small description of the $\mathrm{pH}$ process, an introduction of the dynamic neural units and the fuzzy modeling approaches, the $\mathrm{pH}$ modeling using the combined methods is presented. Several details and comparisons between the developed method, the fuzzy modeling, the recurrent neural networks and the dynamic recurrent neural networks are given. The paper concludes with few final remarks.

\section{THE pH PROCESS DESCRIPTION}

The model of the $\mathrm{pH}$ neutralization process studied in this work is a Continuous Stirred Tank Reactor (CSTR) proposed by McAvoy et al. (1972) [28], and used in our previous work [29], when the full global neural network is implemented in an inexpensive microcontroller, contains two main parts, the first one is dynamic reaction between two inlet streams. The CSTR model is given by the following nonlinear dynamic equations: 


$$
\begin{aligned}
& F_{1} C_{1}-\left(F_{1}+F_{2}\right) \xi=V \frac{d \xi}{d t} \\
& F_{2} C_{2}-\left(F_{1}+F_{2}\right) \zeta=V \frac{d \zeta}{d t}
\end{aligned}
$$

Where $C_{l}$ represents the concentration of the acid inlet stream, $C_{2}$ represents the concentration of base used in the neutralization; $\zeta$ and $\xi$ are the concentration of acid ion and base ion in the reactor, respectively. $F_{1}$ denotes the flow rate of acid inlet stream, $F_{2}$ represents the flow rate of base used in the neutralization and $V$ is the volume of the reactor.

The second part represents a static function. It can be found by writing material balances on $\mathrm{Na}^{+}(\zeta)$ and total acetate (HAC + $\left.\mathrm{AC}^{-}\right)(\xi)$ and assuming that acid-base equilibrium and electroneutrality relationships hold on, one gets:

HAC equilibrium:

$$
\frac{\left[A C^{-}\right]\left[H^{+}\right]}{[H A C]}=K_{a}
$$

Water equilibrium:

$$
\left[\mathrm{H}^{+}\right]\left[\mathrm{OH}^{-}\right]=\mathrm{K}_{w}
$$

Electroneutrality:

$$
\zeta+\left[\mathrm{H}^{+}\right]=\left[\mathrm{OH}^{-}\right]+\left[\mathrm{AC}^{-}\right]
$$

where $K_{a}$ and $K_{w}$ are the dissociation constants of the acetic acid and water.

After inserting the equations (3) and (4) into (5), we have finally the titration function given by the equation (6), which gives the static relationship between $\zeta, \xi$ and the $\mathrm{pH}$ :

$$
\begin{aligned}
& {\left[H^{+}\right]^{3}+\left[H^{+}\right]^{2}\left(K_{a}+\zeta\right)} \\
& +\left[H^{+}\right]\left(K_{a}(\zeta-\xi)-K_{w}\right)-K_{a} K_{w}=0
\end{aligned}
$$

The $\mathrm{pH}$ is given by the equation (7):

$$
p H=-\log _{10}\left[H^{+}\right]
$$

In what follow, the dynamic neural units are used to model the dynamic CSTR model (equations 1 and 2). However, the fuzzy technique is used to identify the static titration function (equations 6 and 7).

\section{DYNAMIC NEURAL UNITS}

A biological neural cell not only contains a nonlinear mapping operation on the weighted sum of its inputs but it also has some dynamic properties such as state feedbacks, time delays hysteresis or limit cycles [3]. In the same reference we find a powerful description of the dynamic neural networks evolution. The dynamic neural units are proposed by Ayoubi [14] which is used in this paper to model a single input multi output of the CSTR model described above.

The neuron transfer function is described by (8), where $y(k)$ is the neuron output at time instant $k . \gamma$ is a nonlinear activity function of the neuron with a threshold $w_{0}$.

$$
y(k)=\gamma\left(\tilde{y}(k), w_{0}\right)
$$

$$
\begin{aligned}
& \tilde{y}(k)=\lambda(k)^{T} \theta \\
& x(k)=w^{T} U
\end{aligned}
$$

$U$ is the data input given by:

$U=\left[u_{1}(k-1) \ldots u_{n}(k-1)\right]^{T}$

Where $n$ is the number of the inputs.

$\lambda(k)$ is the data vector of the dimension [5x1]:

$$
\begin{array}{r}
\lambda(k)=[x(k), x(k-1), x(k-2), \\
-\tilde{y}(k-1),-\tilde{y}(k-2)]^{T}
\end{array}
$$

$\theta$ is the filter coefficients vector of the dimension [5x1]:

$$
\theta=\left[\begin{array}{lllll}
a_{0} & a_{1} & a_{2} & b_{1} & b_{2}
\end{array}\right]^{T}
$$

$x(k)$ is the filter input at time instant $k$, and $w$ is the weights of the neuron input.

The algorithm proposed by Widrow and Heft [30] is used to calculate the optimal parameters. The objective of this algorithm is to adjust the neuron parameters (both the weights and filter coefficients), based on a given set of input-output pairs and to determine the optimal parameters set which minimizes the performance index:

$J=\frac{1}{2} \sum_{k=1}^{N} e^{2}(k)$

where $N$ is the size of the training set. The error signal defined as $e(k)$ is the difference between the desired response $y_{d}(k)$ and the actual neuron response $y(k)$.

The optimal parameters which minimize $J$ are iteratively approximated by moving in the direction of steepest descent on the cost function surface:

$$
\vartheta_{\text {new }}=\vartheta_{\text {old }}+\eta\left\{\sum_{k=1}^{N} e(k) \frac{\partial y(k)}{\partial \vartheta}\right\}
$$

Where $\vartheta$ denotes the network parameters to be adapted and $\eta$ is the learning rate.

\section{FUZZY MODELING}

Fuzzy modeling and identification from measured data are effective tools for the approximation of nonlinear systems [31]. It is based on the clustering technique, in which several methods can be used [32]. Gustafson-Kessel clustering algorithm [33] promises a good approximation of the membership functions. Based on this last one Babuska et al. [34] identify MIMO processes and they prove that such systems can be approximated by a collection of coupled MISO discrete time fuzzy models, a good detail of the fuzzy modeling can be found in [4,5 and 35].

The static MISO models used for the black box input-output are given:

$y(k+1)=\psi\left(u_{n}(k)\right)$

where $u_{n}(k)$ is the $n^{\text {th }}$ input vector. 
The process can be approximated by a MISO static fuzzy model with rules of the following structure:

$$
\begin{aligned}
& R_{j}: \text { If } u_{1} \text { is } A_{1} \text { and } u_{2} \text { is } A_{2} \ldots u_{n} \text { is } A_{n} \text { then } \\
& y(k)=p_{0}+\sum_{i=1}^{n} p_{i} u_{i}(k-1)
\end{aligned}
$$

$A_{i}$ is a matrix with fuzzy sets.

The overall degree of membership of the premise of rule $R_{j}$ can be calculated as:

$\mu_{j}=\min \left[\begin{array}{llll}A_{1} & A_{2} & \cdots & A_{n}\end{array}\right]$

The model output is calculated according to equation (17):

$$
y=\frac{\sum_{j=1}^{m} \mu_{j}(u) y_{j}}{\sum_{j=1}^{m} \mu_{j}(u)}
$$

\section{IDENTIFICATION METHOD}

To identify the $\mathrm{pH}$ process, sequence of input and output data is generated. The input signal is composed of a low-pass filtered Generalized Multiple-level Noise (GMN) signal [36] to which white noise with a small amplitude is added. The low-frequency component signal drives the nonlinear system through the entire operating range, while the high-frequency component takes care for persistent local excitation [34]. The unmeasured states are $\zeta$, $\xi$ and the measured output is the $\mathrm{pH}$ response in the output of the tank. The number of samples available for identification is 30000 and the sample time is $24 \mathrm{sec}$ [37]. The pairs input output are shown in Figure 1.

The dynamic nonlinear identification consists to map the relationship between the flow rate and the states $\zeta, \xi$ on one hand by using the DNUs approach, the states $\zeta$, $\xi$ and output of the $\mathrm{pH}$ response using the fuzzy modeling on the other hand. In this research and because the DNUs take the dynamics inside them, they need just the control input, two dynamic neurons in the hidden layer and the two outputs which estimate the states $\zeta, \xi$. At the beginning of the training procedure, all filter coefficients except $b_{0}$ are initialized to zero. $b_{0}$ is set to one, the weights are initialized randomly smaller. The delta rule which is a Least Mean Squared Error (LMSE) was used as a learning method. A number of 18000 samples are used for the identification and the rest of the signal is used for validation purpose. After convergence the dynamic neural units give excellent predictions where the validation step gives an excellent approximation of the states $\zeta, \xi$ using the optimal founding network parameters given in the table 1 . The results of the training and the validation parts are shown in Figure 2, we note that these results are obtained by using the value $\eta=0.005$ as learning rate and the estimated network output is $\Delta \hat{y}$ rather than $\hat{y}$ [38]. This correction is used to regulate the problem of the overshoot error.

The founding optimal parameters will be used to generate the inputs of the static fuzzy model and also static neural network model for the comparison.

In the fuzzy modeling part, the same data used for the identification with the DNUs is used here, but in this case the fuzzy model inputs are the states $\zeta, \xi$ and the output is the $\mathrm{pH}$. The membership functions found using Gustafson-Kessel clustering algorithm are given in figure 3 , and the optimal three rules (if-then rules) to estimate the $\mathrm{pH}$ output are given as follow:

$$
\begin{aligned}
& \boldsymbol{R}_{1}: \quad \text { If } \zeta \text { is } A_{1} \text { and } \xi \text { is } B_{1} \text { then } \\
& \Delta p \hat{H}(k+1)=-12.8 \zeta(k)-15.9 \xi(k)+15.6 \\
& \boldsymbol{R}_{2}: \quad \text { If } \zeta \text { is } A_{2} \text { and } \xi \text { is } B_{2} \text { then } \\
& \Delta p \hat{H}(k+1)=3.77 \times 10^{-2} \zeta(k)+4.66 \times 10^{-2} \xi(k)-4.60 \times 10^{-2} \\
& \boldsymbol{R}_{3}: \quad \text { If } \zeta \text { is } A_{3} \text { and } \xi \text { is } B_{3} \text { then } \\
& \Delta p \hat{H}(k+1)=-2.32 \times 10^{-2} \zeta(k)-2.25 \times 10^{-2} \xi(k)+2.65 \times 10^{-2}
\end{aligned}
$$

It can be noticed that the estimated output is the $\Delta p \hat{H}(k)$ rather than $p \hat{H}(k)$ which gives better results, and in the objective to not move away the aim of this paper, we will describe the feasibility and the performance of this method in another paper. In this case the estimated resulting $p \hat{H}(k)$ is $p \hat{H}(k+1)=\Delta p \hat{H}(k)+p \hat{H}(k)$.

The rest of the data (12000 samples) is used to validate the whole model. In other words, introducing new command signal to the DNUs model will generate the states $\zeta, \xi$ using the optimal parameters of the table 1 , the resulting estimated states will be entered into the fuzzy model which will predict in its part the $\mathrm{pH}$ difference and in which we add the past $\mathrm{pH}$ value $p \hat{H}(k)$ to find the final estimated $p \hat{H}(k+1)$. All these operations are called the model generalization results presented in the Figure 4.

Again, the response of the validated Dynamic Neural UnitsFuzzy (so-called DNU-Fuzzy) is presented versus the modeled $\mathrm{pH}$ response as desired system output. Based on these results and for the fact that these errors hardly differ from the training mean square errors, the number of parameters in the different architectures and the training times except the fuzzy modeling, gives better training time but it is the worst case in the MSE results (Table 2). Hence, the proposed architecture proves good identification quality. 

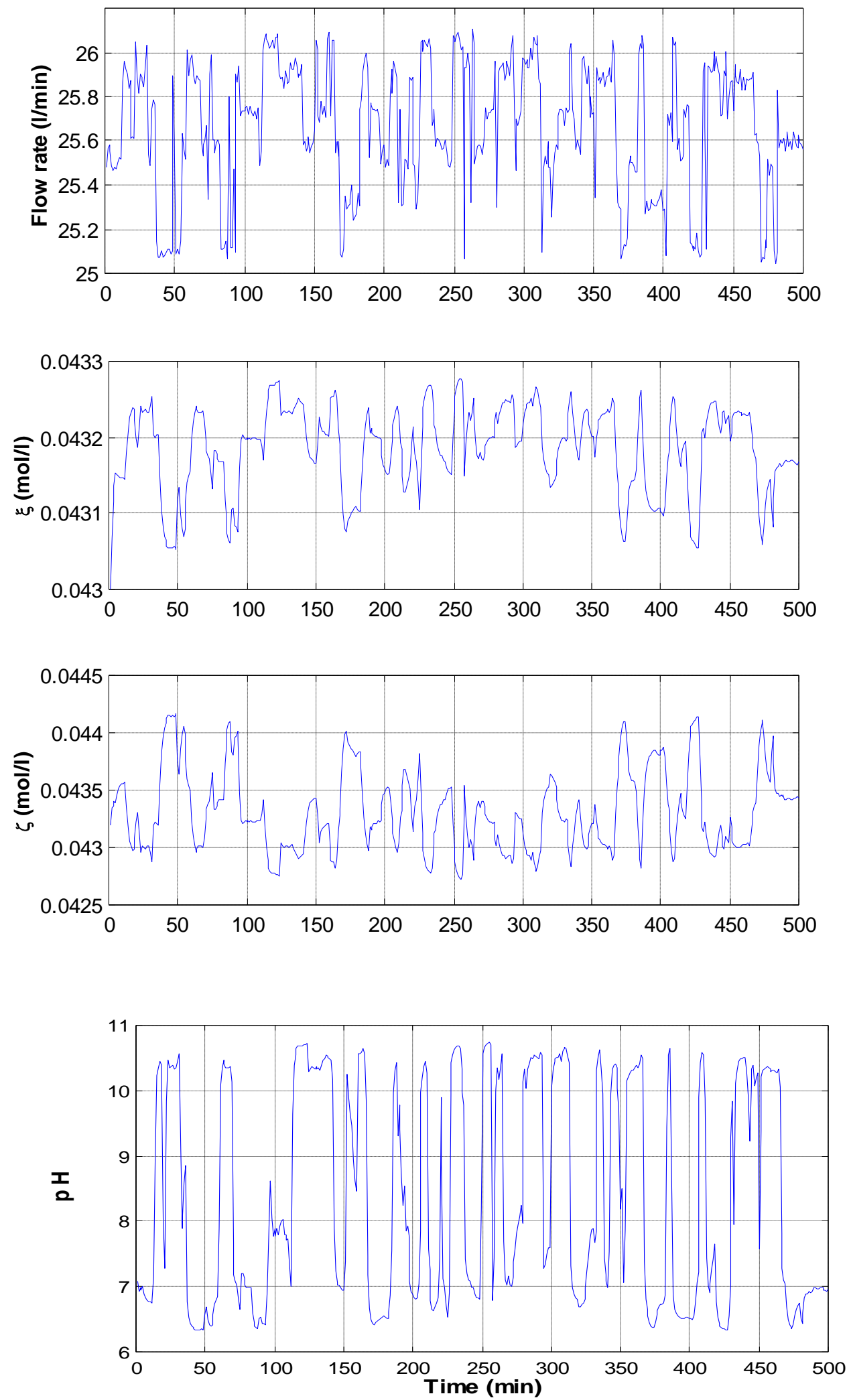

Fig 1: The flow rate, the states $\zeta, \xi$ and $\mathrm{pH}$ response used for the identification and for the validation. 

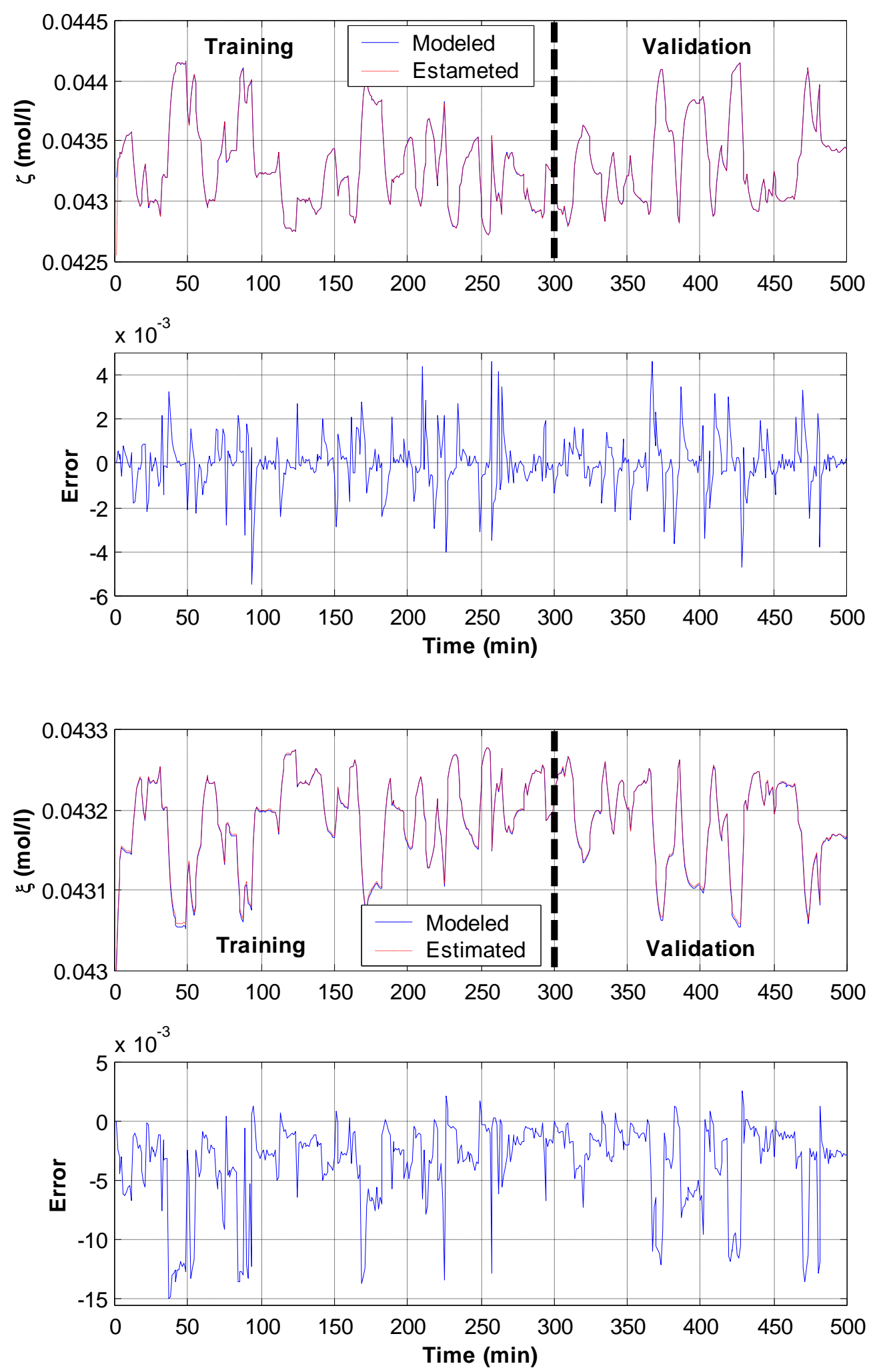

Fig 2: Identification and validation the states $\zeta, \xi$ using the DNUs. 
Table 1. The optimal parameters of the DNUs

\begin{tabular}{|c|c|}
\hline \multicolumn{2}{|c|}{ The optimal DNUs parameters } \\
\hline $\begin{array}{l}\text { Filters parameters } \\
{\left[\begin{array}{ccccc}b_{0}^{i} & b_{1}^{i} & b_{2}^{i} & a_{1}^{i} & a_{2}^{i}\end{array}\right]} \\
\text { Neuron } i=1 . .2 .\end{array}$ & {$\left[\begin{array}{lllll}1.19490 & 0.19459 & 0.19436 & -0.49612 & -0.49530 \\
1.19220 & 0.19221 & 0.19232 & -0.45573 & -0.45611\end{array}\right]$} \\
\hline $\begin{array}{l}\text { Weights } w_{i j} \text { for the } \\
\text { neuron } j \text { and the } \\
\text { input } i\end{array}$ & {$\left[\begin{array}{l}-0.31931 \\
-0.21632\end{array}\right]$} \\
\hline $\begin{array}{l}\text { thresholds } c_{j} \text { for } \\
\text { the the output } j\end{array}$ & {$\left[\begin{array}{l}-2.474 \\
-3.962\end{array}\right]$} \\
\hline
\end{tabular}

\section{CONCLUSIONS}

In this paper a new architecture based on dynamic neural units and fuzzy logic approaches is proposed to model the dynamic response of $\mathrm{pH}$ process in a CSTR. The obtained results using the DNU-Fuzzy were compared to those obtained using the combined dynamic neural units and static neural networks, the recurrent neural networks and the fuzzy modeling.

According to the obtained results, it is clear that the use of the DNU-Fuzzy to model the $\mathrm{pH}$ process model is more suitable, in the sense that the application of this architecture to identify the nonlinear dynamic $\mathrm{pH}$ model. Many difficulties such as the problem to find an appropriate regressor, the long training times, the large network sizes, etc. could be overcome using this approach.
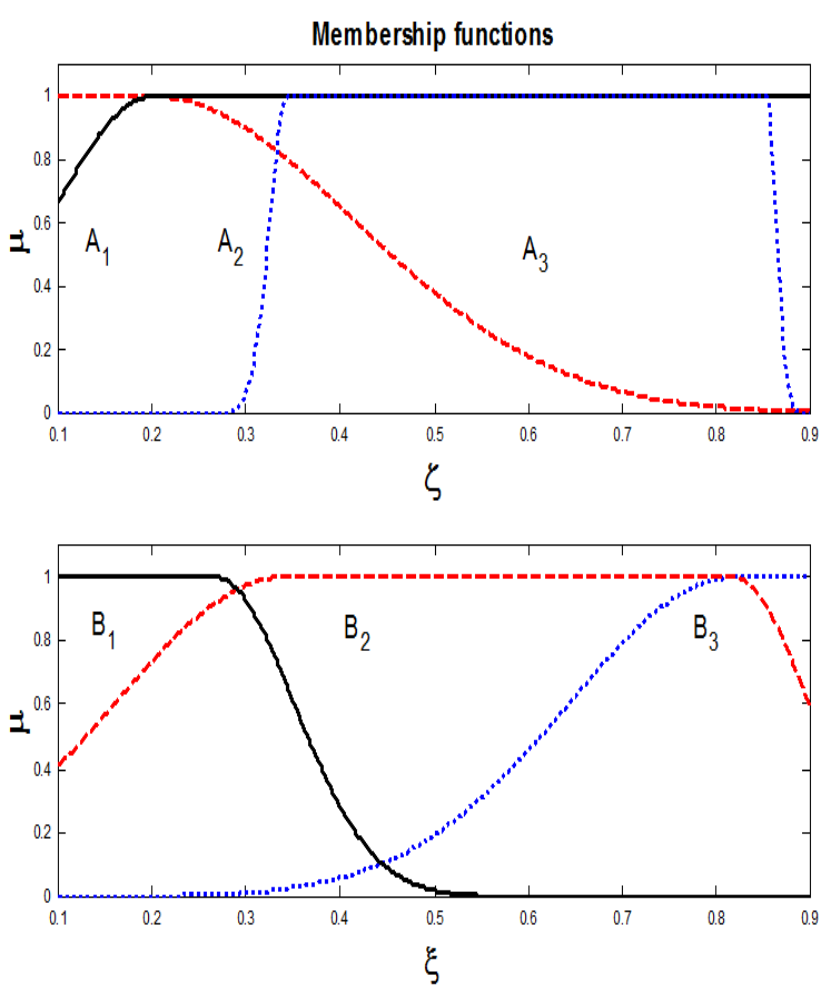

Fig 3: The founding membership functions

Table 2. Comparison results between the recurrent neural networks, the fuzzy modeling, the dynamic neural units-static neural network and dynamic neural units-fuzzy

\begin{tabular}{|c|c|c|c|}
\hline & Training Time in second & $\begin{array}{c}\text { Last mean square } \\
\text { error }\end{array}$ & Structure \\
\hline $\begin{array}{l}\text { Recurrent Neural Network for SISO Model } \\
{\left[\mathrm{F}_{2}, \mathrm{pH}\right] \text { with delay inputs and outputs }}\end{array}$ & $\begin{array}{c}190.180 \\
\text { For } 100 \text { iterations }\end{array}$ & 1.95110 & $\begin{array}{c}36 \text { parameters } \\
5 \text { inputs, one output }\end{array}$ \\
\hline $\begin{array}{c}\text { Fuzzy modeling for SISO Model } \\
{\left[\mathrm{F}_{2}, \mathrm{pH}\right] \text { without delay inputs and outputs }}\end{array}$ & 3.084 & 6.77100 & 3 clusters \\
\hline $\begin{array}{c}\text { Dynamic Neural Units-Static Neural Network } \\
\text { SIMO-MISO model } \\
{\left[\left(\mathrm{F}_{2}, \zeta \xi\right) ;(\zeta \xi, \mathrm{pH})\right] \text { without delay inputs and }} \\
\text { outputs }\end{array}$ & $\begin{array}{l}160.35+15.005=175.355 \\
\text { For } 30 \text { iterations in the } \\
\text { DNU part and } 10 \text { iterations } \\
\text { for the static part }\end{array}$ & $\begin{array}{l}0.25142+0.74829= \\
0.99971\end{array}$ & $\begin{array}{l}14 \text { parameter DNU and } \\
21 \text { parameter for the static } \\
\text { neural network }\end{array}$ \\
\hline $\begin{array}{c}\text { Dynamic Neural Units-Fuzzy (DNU-Fuzzy) } \\
\text { SIMO-MISO model } \\
{\left[\left(\mathrm{F}_{2}, \zeta \xi\right) ;(\zeta \xi, \mathrm{pH})\right] \text { without delay inputs and }} \\
\text { outputs }\end{array}$ & $\begin{array}{c}160.35+2.853=163.200 \\
\text { For } 30 \text { iterations in the } \\
\text { DNU part }\end{array}$ & $\begin{array}{l}0.25142+0.25235= \\
0.50377\end{array}$ & $\begin{array}{l}14 \text { parameter DNU } \\
3 \text { clusters }\end{array}$ \\
\hline
\end{tabular}



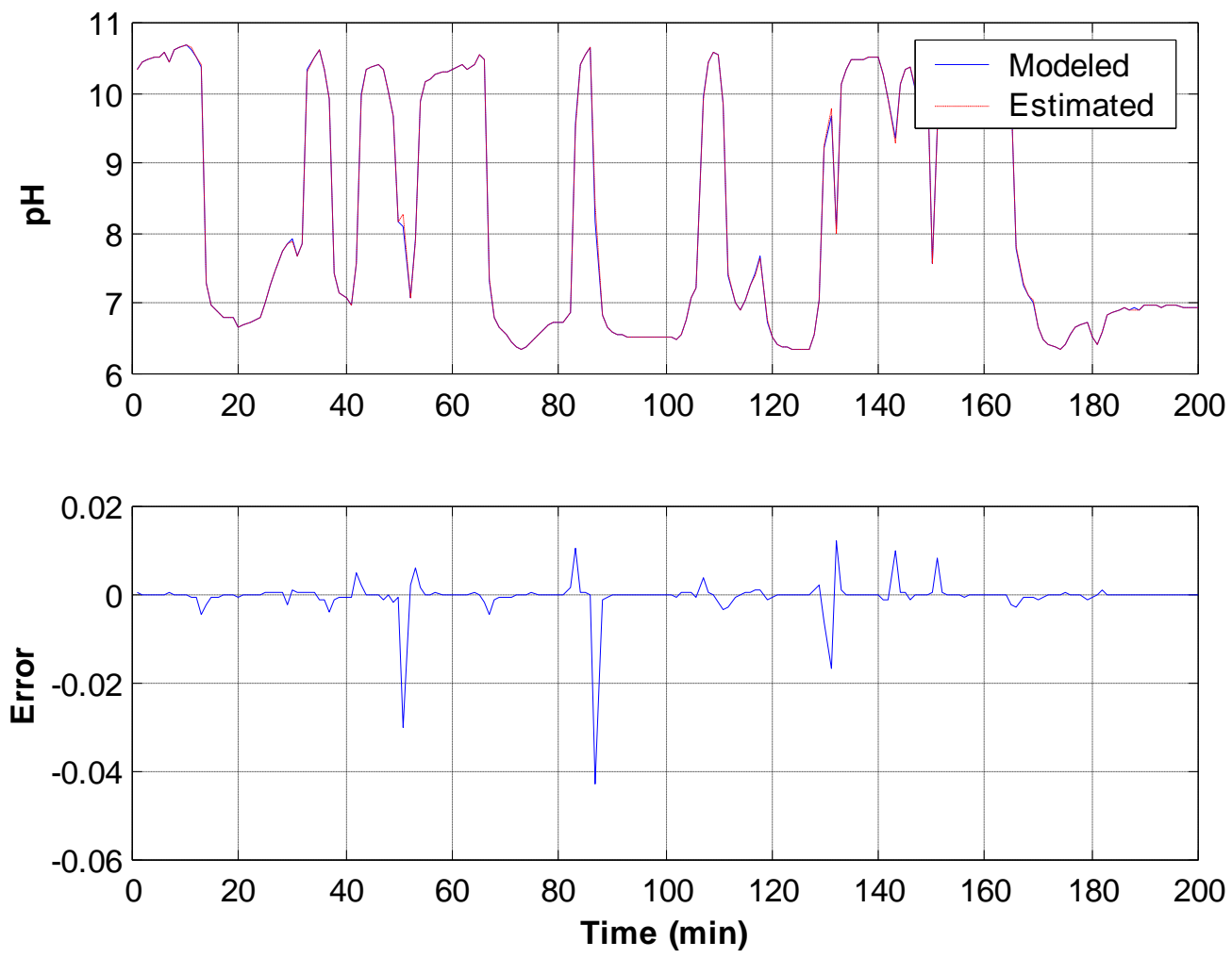

Fig 4: The fuzzy modeling of the static titration function

\section{REFERENCES}

[1] G. Lightbody, G. Irwin. 1997. Nonlinear control structures based on embedded neural system models. IEEE Trans. on Neural Networks, 8, pp. 553-567.

[2] Narendra, K. S. and Parthasarathy, K. 1990. Identification and Control Of Dynamical Systems Using Neural Networks. IEEE Trans. on Neural Networks, 1 (1), 4-27.

[3] Patan, K. 2008. Artificial Neural Networks for the Modelling and Fault Diagnosis of Technical Processes. Springer-Verlag Berlin Heidelberg.

[4] Roffel, B. and Betlem, B. 2006. Process Dynamics and Control, Modeling for Control and Prediction. John Wiley $\&$ Sons.

[5] Babuska, R. 1998. Fuzzy Modeling for Control. Kluwer Academic Publishers, Boston.

[6] Aoyama A., Doyle III F.J. and Venkatasubramanian V. 1995. A Fuzzy Neural-network Approach for Nonlinear Process Control', Engineering Applications of Artificial Intelligence, 8(5), 483-498.

[7] Vieira, J., Dias, F.M. and Mota, A. 2004. Artificial neural networks and neuro-fuzzy systems for modelling and controlling real systems a comparative study', Engineering Applications of Artificial Intelligence, 17, 265-273.

[8] Zhang, J. and Morris, A.J. 1995. Fuzzy neural networks for nonlinear systems modeling. IEE Proceedings on Control Theory Applications, 142(6), 51-561.
[9] Jang, JS. R., Sun CT. and Mizutani, E. 1997. Neuro-Fuzzy and Soft Computing. A Computational Approach to Learning and Machine Intelligence. Prentice Hall.

[10] Alavala, C.R. 2008. Fuzzy Logic and Neural Networks Basic Concepts and Applications. New Age International Publishers.

[11] Nelles, O. 2001. Nonlinear system identification from classical approaches to neural networks and fuzzy models. Springer-Verlag.

[12] Rutkowski, L. 2004. Flexible Neuro Fuzzy Systems Structures Learning and Performance Evaluation. Kluwer Academic Publishers, Boston.

[13] Gupta, M.M. Jin, L. Homma, N. 2003. Static and dynamic neural networks: from fundamentals to advanced theory. Wiley-IEEE Press, New York.

[14] Ayoubi, M. 1994. Nonlinear dynamic systems identification with dynamic neural networks for fault diagnosis in technical protests. In: IEEE international conference systems man and Cyberntics SMC'94 USA, 2120-2125.

[15] Saad Saoud, L. and Khellaf, A. 2009. Identification and Control of a Nonlinear Chemical process Plant Using Dynamical Neural Units.' Third International Conference on Electrical Engineering Design and technologies, Tunisia, October 31- November 2. 
[16] Yeo, Y. K. and Kwon, T. I. 2004. Control of pH Processes Based on the Genetic Algorithm', Korean Journal of Chemical Engineering, 21(1), 6-13.

[17] Lazar, C. Pintea, R. and De Keyser R. 2007. Nonlinear predictive control of a $\mathrm{pH}$ process'. 17th European Symposium on Computer Aided Process Engineering, 24, 829-834.

[18] N Bhat, N. and McAvoy, T.J. 1990. Use of neural nets for dynamic modeling and control of chemical process systems'. Computers and Chemical Engineering, 14(4/5), 573-583.

[19] Loh, A.P. Looi, K.O. and Fong, K.F. 1995. Neural network modelling and control strategies for a $\mathrm{pH}$ process. Journal of Process Control, 5(6), 355-362.

[20] Nie, J. Loh, A.P. and Hang, C.C. 1996. Modeling pH neutralization processes using fuzzy-neural approaches'. Fuzzy Sets and Systems, 78, 5-22.

[21] Li, N. Li, S. and Xi, Y. 2001. Modeling pH Neutralization Process using Fuzzy Satisfactory Clustering. Fuzzy Systems, $308-311$.

[22] Chen, J. and Huang, T.C. 2004. Applying neural networks to on-line updated PID controllers for nonlinear process control'. Journal of Process Control, 14, 211-230,

[23] Akesson, B.M., Toivonen, H.T. and Waller, J.B. 2005. Neural network approximation of a nonlinear model predictive controller applied to a $\mathrm{pH}$ neutralization process. Computers and Chemical Engineering, 29, 323-335.

[24] Duan, S., Shi, Z., Feng, H. Duan, Z. and Mao, Z. 2006. An on-line adaptive control based on DO-pH measurements and ANN pattern recognition model for fed-batch. Biochemical Engineering Journal, 30, 88-96.

[25] Norquay, S.J., Palazoglu, A. and Romagnoli, J.A. 1999. Application of Wiener model predictive control (WMPC) to a $\mathrm{pH}$ neutralization experiment. IEEE Transactions On Control Systems Technology, 7(4), 437 - 445.

[26] Gomez, J.C., Jutan, A. and Baeyens, E. 2004. Wiener model identification and predictive control of a $\mathrm{pH}$ neutralization process. IEE Proceedings on Control Theory Applications, 151(3), 329 - 338.
[27] Arefi, MM., Montazeri, A., Poshtan J. and Jahed-Motlagh, MR. 2006. Nonlinear Model Predictive Control of Chemical Processes with a Wiener Identification'. IEEE International Conference on Industrial Technology, 15-17 (Dec. 2006), 1735 - 1740, Mumbai.

[28] McAvoy, T., Hsu E. and Lowenthal, S. 1972. Dynamics of $\mathrm{pH}$ in CSTRs. Industrial and Engineering Chemistry Process Design and Development, 11, 68-70.

[29] Saad Saoud, L. and Khellaf, A. 2011. A Neural Network Based on an Inexpensive Eight Bit Microcontroller. Neural computing and application, 20(3), 329-334.

[30] Widrow, B. and Holt, M. 1960. Adaptive Switching Circuits'. IRE WESCON Convention Record., New York, 96-104.

[31] Chafaa, K., Ghanai, M. and Benmahammed, K. 2007. Fuzzy modelling using Kalman filter. IET Control Theory Applications,, 1(1), 58-64.

[32] Karaboga, D. and Ozturk, C. 2010. Fuzzy clustering with artificial bee colony algorithm'. Scientific Research and Essays, 5(14), 1899-1902.

[33] Gustafson, D.E. and Kessel, W.C. 1979. Fuzzy clustering with a fuzzy covariance matrix. In Proc. IEEE CDC, 761766, San Diego, CA, USA,

[34] Babuska, R. Roubos J.A. and Verbruggen, H.B. 1998 .Identification of MIMO systems by input-output TS fuzzy models. The IEEE World Congress on Computational Intelligence, Vol.1, (4-9 May 1998), 657 - 662.

[35] Zhang, H. and Liu, D. 2006. Fuzzy Modeling and Fuzzy Control. Birkhauser, Boston,

[36] Zhu, Y. 2001. Multivariable System Identification for Process Control. Pergamon, An imprint of Elsevier Science.

[37] Doherty, S. K. 1999. Control of $\mathrm{pH}$ in chemical processes using artificial neural networks. Ph. D thesis, School of Engineering, Liverpool John Moores University,

[38] Mokhtari, M. and Marie, M. 1998. Applications of Matlab 5 and Simulink 2. Springer-Verlag, France (in French). 